\title{
Cariogenicity of Candida albicans of distinct genotypes among 3-5-year-old Uygur children in Kashgar, China- a case-control study
}

\author{
Wanting Zhang ${ }^{1}$, Yan Li ${ }^{1}$, Jing Lin ${ }^{1}$, Aynur Abduryim² and Jin Zhao ${ }^{1 *}$ (D)
}

\begin{abstract}
Background: In recent years, the opportunistic fungus C.albicans has been linked to ECC.It is important to investigate the relationship between the distribution of C.albicans and early childhood caries (ECC) in 3-5-year-old Uygur and Han children in Kashgar, and the role of C.albicans of distinct genotypes in caries.

Methods: Two hundred fifty-six Uygur and 141 Han children were enrolled in the study. The identified C.albicans isolates were genotyped based on 25S rDNA Polymerase Chain Reaction(PCR) amplification, and their acidogenicity, aciduricity, and adhesiveness were examined. Moreover, secreted aspartic protease (Sap) activity and SAP1-5 transcriptional levels were compared in the ECC and caries-free (CF) groups of Uygur children.

Results: C.albicans detection rate was significantly higher in Uygur children than in Han children (44. 5\% vs. 31. 2\%; $X 2=6.739, P=0.009)$; the A genotype was dominant in Uygur and Han children with ECC, the C genotype was dominant in Uygur CF children $(P=0.022)$. C.albicans acidogenicity and growth were more pronounced in the Uygur ECC group than in CF group, especially at $\mathrm{pH} 4.0$ and $4.5(\mathrm{pH} 4.0, P=0.012 ; \mathrm{pH} 4.5, P=0.029)$; the average ratios of glass-wall adhesion and the Sap activity was higher in ECC group than in CF group $(P<0.01)$, and $\operatorname{SAP2}(P<0.001)$ and SAP5 $(P=0.001)$ were expressed more robustly in ECC group.

Conclusions: The strong acidogenicity and aciduricity, Sap activity, and high SAP2 and SAP5 expression might be closely associated with ECC. C.albicans potentially plays a key role in the progression of caries, which most readily affects genotype A carriers and could be attributed to person-to-person environmental variation.
\end{abstract}

Keywords: Early childhood caries, Candida albicans, Ethnicity, Cariogenicity, Genotype

\section{Background}

Early childhood caries (ECC) is the most common disease in children [1]. Numerous epidemiological studies have demonstrated that the prevalence of ECC is lower in developed countries than in developing countries with low socioeconomic status [2, 3]. Hence, children in underdeveloped regions might be at a higher risk of caries, and stringent measures must be employed to treat them [4]. ECC is recognized as caused by a combination of diverse microorganisms and multiple factors. The

\footnotetext{
* Correspondence: merryljin@sina.com

${ }^{1}$ Department of Endodontics, The First Affiliated Hospital of Xinjiang Medical University, Urumqi, Xinjiang 830054, China

Full list of author information is available at the end of the article
}

research on ECC-associated microorganisms has mainly focused on the bacteria Streptococcus mutans, Lactobacillus, and Actinomyces [5]. In recent years, the opportunistic fungus C.albicans has also been linked to ECC: it is detected in the saliva, plaque, and caries tissues, and the detection rate is markedly higher in children with ECC than in caries-free (CF) [6].

Dental plaque, a microecological environment, where the microbes survive closely attached to the tooth surface, slows the local diffusion of saliva, enabling a continuous partial activity of acids; once the cariogenic $\mathrm{pH}$ (5. 4, 5. 5) is reached, enamel demineralization occurs, with caries formation [7]. C.albicans ferments various sugars and produces acids; it can reduce the $\mathrm{pH}$ of a 
sugary broth from 7.0 to 3.5 , potentially leading to tooth demineralization [8]. A key C.albicans virulence factor is secreted aspartic protease(Sap; gene:SAP), it can promotes C.albicans adhesion to tooth surface [9]. The probability and intensity of the disease caused by C.albicans of distinct genotypes are different, which may correlate with the ethnic and regional disparities between different geographical areas, and C.albicans strains harboured by different groups of people harbour distinct genes [10]. Until now, only a few studies have examined C.albicans gene polymorphism in relation to the underlying mechanism of caries, and fewer still have investigated the influence of ethnic and geographic factors.

Xinjiang province is located in Northwestern China, with the Uygur people as the predominant ethnic minority group. The incidence of ECC among 3-5-year-olds in Kashgar city is $74.58 \%$ [11], which is markedly higher than the average level of China. This suggested that these children are particularly ECC-prone. The Uygur account for 91.92\% of the total population in Kashgar; Kashgar's history, geography, and local customs render the city a isolated area with a unique representation of the Chinese population. Hence, in the current study, we investigated C.albicans distribution, and the relationship between C.albicans and ECC in 3-5-year-old children in Kashgar. We also examined the role of C.albicans of distinct genotypes in the mechanism of caries development, providing a theoretical reference point for dental caries prevention.

\section{Methods}

\section{Study participants}

This study was approved by the First Affiliated Hospital of Xinjiang Medical Ethics Committee (ethical review number 20150214-162), and the local heath administrative departments. We used the following sample size estimation formula $[10,12]$ :

$$
\begin{aligned}
1 \mathrm{~N} & =\left(\mathrm{Z}_{1-\mathrm{a} / 2}+\mathrm{Z}_{1-\beta}\right)^{2}\left[\mathrm{p}_{1}\left(1-\mathrm{p}_{1}\right)+\mathrm{p}_{2}\left(1-\mathrm{p}_{2}\right)\right] / \delta^{2} \\
& =(1.96+1.28)^{2}[0.5 *(1-0.5)+0.75 *(1-0.75)] /(0.75-0.5)^{2} \\
& =73.5
\end{aligned}
$$

This yielded a minimum total sample size of 296 .

After applying the stratified cluster-sampling method, 397 3-5-year-old children were enrolled in the study. The children were healthy; presented no systemic, hereditary, or mucous diseases; did not wear orthodontic appliances; and had not received any antibiotic drugs or injections within $30 \mathrm{~d}$ prior to sampling. Written consent was obtained from the parents (legal guardians) before sampling.

\section{Oral examination and specimen collection}

Two trained oral physicians checked 20 teeth of each child. The children were divided into ECC and CF groups. ECC is usually defined as the presence of one or more decayed (both noncavitated or cavitated lesions), missing (due to caries), or filled tooth surfaces in any primary tooth in a child under the age of six (by AAPD). The inter-examiner reproducibility was 0.83 , and the intra-examiner reproducibility was 0.81 .The children rinsed their mouths before sampling; the dental plaques were collected by a sterilized caries excavator from the third cervical on the buccal side of the first maxilla and the mandibular deciduous molar, and one third lips of the upper anterior teeth [10]. The samples were placed in $1.5 \mathrm{~mL}$ sterile Sabouraud liquid medium (SDB)maintained $4{ }^{\circ} \mathrm{C}$, and returned to the laboratory within $2 \mathrm{~h}$.

\section{Isolation and purification of C.albicans}

Each sample $(20 \mu \mathrm{L})$ was used to inoculate on CHROMagar $(\mathrm{CAC})$ medium and cultured aerobically at $37^{\circ} \mathrm{C}$, the colonies were evaluated after $24-72 \mathrm{~h}$. Emerald green single colonies were picked and streaked on another CAC plate, the procedure was repeated three times.

\section{Identification of C.albicans}

The morphology of cells from C.albicans colonies were examined under a microscope after Gram staining. For germ-tube experiments, microbial suspensions and bovine serum were mixed, placed in a moist dish, incubated at $37^{\circ} \mathrm{C}$; samples were stained every $60 \mathrm{~min}$, and examined cell morphology.

C. albicans was also identified by PCR. Fungal DNA was extracted using the Biospin DNA extraction kit. The following primers were used: ITS1 (5'-GGAAGTAAA AGTCGTAACAAGG-3') and ITS2 (5'-GCTGCGTTC TTCATCGATGC- $\left.3^{\prime}\right)$. The PCR mixture contained $2 \times$ Easy Taq PCR supermix $(10 \mu \mathrm{L}), 10 \mu \mathrm{mol} \cdot \mathrm{L}^{-1}$ of forward and reverse primers $(0.5 \mu \mathrm{L}$ each), DNA template $(2.0 \mu \mathrm{L})$, and $\mathrm{ddH}_{2} \mathrm{O}(7.0 \mu \mathrm{L})$. The cycling conditions were as follows: $95^{\circ} \mathrm{C}$ hot-start, $5 \mathrm{~min}$; followed by 40 cycles of $95^{\circ} \mathrm{C}$ for $30 \mathrm{~s}, 50^{\circ} \mathrm{C}$ for $30 \mathrm{~s}, 72^{\circ} \mathrm{C}$ for $30 \mathrm{~s}$; and $72^{\circ} \mathrm{C}$ for $10 \mathrm{~min}$. The PCR products were imaged using a UV gel scanner after agarose electrophoresis.

Following identification, 20 C.albicans strains were randomly selected from ECC and CF Uygur children, and from ECC Han children for subsequent genotyping.

\section{S rDNA PCR-based C. albicans genotyping}

The 25S rDNA PCR amplification mixture contained $2 \times$ Easy Taq PCR supermix $(15 \mu \mathrm{L}), 10 \mu \mathrm{mol} \cdot \mathrm{L}^{-1}$ of forward and reverse primers $(1.0 \mu \mathrm{L}$ of each), DNA template $(2.5 \mu \mathrm{L})$, and $\mathrm{ddH}_{2} \mathrm{O}(10.5 \mu \mathrm{L})$; the following primers were used: CA-INT-L (5' -ATAAGGGAAGTCG GCAAAATAGATCCGTAA-3') and CA-INT-R (5'-CCT TGGCTGTGGTTTCGCTAGATAGTAGAT-3'). The cycling conditions were as followed: $94{ }^{\circ} \mathrm{C}$ hot-start, $3 \mathrm{~min}$; 
30 cycles of denaturation at $94{ }^{\circ} \mathrm{C}$ for $1 \mathrm{~min}$, annealing at $67^{\circ} \mathrm{C}$ for $1 \mathrm{~min}$, extension at $72^{\circ} \mathrm{C}$ for $2.5 \mathrm{~min}$; and final extension at $72{ }^{\circ} \mathrm{C}, 7 \mathrm{~min}$. The different genotypes were determined based on the sizes of amplification product bands.

\section{Acidogenicity and aciduricity test}

SDB media containing different glucose concentrations (0.01-0. $\left.2 \mathrm{~mol} \cdot \mathrm{L}^{-1}\right)$ and at different $\mathrm{pH}$ values(4.0-7.0) were prepared. Microbial suspensions were adjusted to $\mathrm{OD}_{540}=1.0$, inoculated into $\mathrm{SDB}[1: 10(\mathrm{v} / \mathrm{v})$ ratio $]$, and aerobically cultured at $37{ }^{\circ} \mathrm{C}$ for $48 \mathrm{~h}$. Next, each suspension was centrifuged $\left(15 \mathrm{~min}, 5000 \mathrm{rpm} \times g, 4{ }^{\circ} \mathrm{C}\right)$, and the supernatant was transferred to another tube. The $\mathrm{pH}$ of the supernatant (terminal $\mathrm{pH}$ ) was measured and the $\mathrm{pH}$ change calculated $[\Delta \mathrm{pH}=\mathrm{pH}($ initial $)-\mathrm{pH}($ terminal $)]$. The collected C.albicans pellet was diluted in $4 \mathrm{~mL}$ of sterile saline, vortex-mixed, and shocked for $25 \mathrm{~s}$; $\mathrm{OD}_{540}$ was then measured, with the sterile saline as a blank. Each sample was tested three times and the results were averaged.

\section{Adhesiveness test}

Microbial suspensions $\left(1 \mathrm{~mL} ; \mathrm{OD}_{540}=1.0\right)$ were added to $\mathrm{SDB}(1 \mathrm{~mL})$, the tubes tilted at $30^{\circ}$, and cultured aerobically at $37^{\circ} \mathrm{C}$, overnight. Next, the tube containing the suspension (tube no. 1) was gently rotated three times. The content was transferred to a clean tube (tube no. 2); $6 \mathrm{~mL}$ of PBS was placed in tube 1, which was again gently rotated three times. The tube contents were transferred to a third tube (tube no. 3) [13]. Tubes no. 2 and 3 were centrifuged $(10,000 \mathrm{rpm}, 10 \mathrm{~min})$, and the supernatant removed; $6 \mathrm{~mL}$ of PBS was placed in tubes no. $1-3$, and the contents mixed evenly. Next, $\mathrm{OD}_{540}$ of tube no. 1-3 contents was measured. The microbial adhesion ratio was calculated as follows: adhesion ratio = OD $1 /(\mathrm{OD} 1+\mathrm{OD} 2+\mathrm{OD} 3) \times 100 \%$. Each sample was evaluated three times and the data were averaged.

\section{C. albicans sap activity}

For the YNB-BSA-agar method [14]; C.albicans suspensions were adjusted to $10^{6} \mathrm{CFU} \cdot \mathrm{mL}^{-, 1} 5 \mu \mathrm{L}$ drops were pipetted onto YNB-BSA agar in triplicate, and the plates incubated aerobically at $37^{\circ} \mathrm{C}$ for $72 \mathrm{~h}$. The protease activity $(\mathrm{Pa})$ was calculated as the ratio of colony diameter to colony-and-halo diameter.

For the MTT assay with BSA as substrate, microbial suspensions were diluted to $10^{6} \mathrm{CFU} \cdot \mathrm{mL}^{-1}$ and centrifuged $\left(1500 \mathrm{rpm}, 4{ }^{\circ} \mathrm{C}, 10 \mathrm{~min}\right)$; the supernatants were added to $0.1 \mathrm{~mol} \cdot \mathrm{L}^{-1}$ of citrate buffer containing $0.2 \%$ BSA, and incubated aerobically at $37^{\circ} \mathrm{C}$ for $30 \mathrm{~min}$. The reaction was terminated by the addition of $10 \%(w / v)$ trichloroacetic acid; the samples were then centrifuged
(1300 rpm, $4{ }^{\circ} \mathrm{C}, 30 \mathrm{~min}$ ), and $\mathrm{OD}_{280}$ of the supernatant was measured. Next, the microbial suspension was transferred, in triplicate, to 96 -well plates $(200 \mu \mathrm{L}$ per well); $20 \mu \mathrm{L}$ of MTT was added to each well, and the plates were incubated in the dark $\left(37^{\circ} \mathrm{C}, 4 \mathrm{~h}\right)$. Finally, the supernatant was collected, mixed with dimethyl sulphoxide $(150 \mu \mathrm{L})$, and agitated gently for $10 \mathrm{~min}$; $\mathrm{OD}_{490}$ of each sample was then measured. The increase in absorbance corresponded to Sap activity (calculated as the $\mathrm{OD}_{280} / \mathrm{OD}_{490}$ ratio) [15].

\section{SAP1-5 gene expression}

Total RNA was extracted from C.albicans cells and then reverse-transcribed to cDNA using a cDNA synthesis kit. RT-PCR quantification of SAP1-5 expression was performed in $20 \mu \mathrm{L}$ reaction mixtures containing cDNA template $(2 \mu \mathrm{L}), 10 \mu \mathrm{mol} \cdot \mathrm{L}^{-1}$ of forward and reverse primers (0. $5 \mu \mathrm{L}$ each;Table 1), $5 \times$ SYBR Green I PCR buffer $(10 \mu \mathrm{L})$, and $\mathrm{ddH}_{2} \mathrm{O}(7.0 \mu \mathrm{L})$. The cycling conditions were as follows: initial denaturation at $95^{\circ} \mathrm{C}$ for $30 \mathrm{~s}$; followed by 40 cycles of denaturation at $95^{\circ} \mathrm{C}$ for $5 \mathrm{~s}$, elongation at $60{ }^{\circ} \mathrm{C}$ for $30 \mathrm{~s}$. The results were then analysed.

\section{Statistical analysis}

Data were analysed using SPSS 21.0. For categorical data, $\chi^{2}$ test was used ( $\alpha=0.05$, two-sided). For continuous data,when normality and homogeneity were detected, $t$ test or the nonparametric rank-sum test was used. Finally, factorial analysis was employed to evaluate data from the following experiments: acidogenicity and aciduricity $(\Delta \mathrm{pH}, \Delta \mathrm{OD})$, adhesion ratio, Sap activity, and SAP1-5 expression in C.albicans isolates of different genotypes. The differences were considered statistically significant when $P<0.05$.

Table 1 Primers for SAP $1-5$ and GAPDH

\begin{tabular}{lll}
\hline Primer name & Primer sequence & $\begin{array}{l}\text { Fragment } \\
\text { length }(\mathrm{bp})\end{array}$ \\
\hline SAP1 & F TCAATCAATTACTCTTCCATTTCTAACA & 161 \\
& RCCAGTAGCATTAACAGGAGTTTAATGACA & \\
SAP2 & F TGGATTGGTGGTGTTCGA & 108 \\
& R CCACCGGCTTCATTGGTT & \\
SAP3 & F CCTTCTCTAAAATATGGATTGGAAC & 231 \\
& R TTGATTCACCTTGGGGCCAGTAACATT & \\
SAP4 & F CATTCATTCCTTAATACCGACTATC & 156 \\
& R GGTAACAAACCCTGTAGATCTTTAAC & \\
SAP5 & F TGGTGGTATTGACAAGGCCA & 107 \\
& R TTCGTCCCCTAACATTGACAGAT & \\
GAPDH & F TTGACGGTCCATCCCACAA & 103 \\
& R GGAATAACCTTACCAACGGCTT & \\
\hline
\end{tabular}


Table 2 The distribution of C.albicans among Uygur and Han children

\begin{tabular}{|c|c|c|c|c|c|c|c|c|}
\hline \multirow[t]{2}{*}{ Ethnicity } & \multicolumn{2}{|l|}{ Caries } & \multirow[t]{2}{*}{$\mathrm{P}$} & \multicolumn{2}{|l|}{ Gender } & \multirow[t]{2}{*}{$P$} & \multirow[t]{2}{*}{ Total } & \multirow[t]{2}{*}{$P$} \\
\hline & ECC (\%) & CF (\%) & & Male & Female & & & \\
\hline Uygur & 92/176 (52. 3) & 22/80 (27. 5) & $<0.001$ & $66 / 129$ (51. 2) & 48/127 (37.8) & 0.031 & $114 / 256(44.5)$ & 0.009 \\
\hline Han & $32 / 78(41.0)$ & 12/63 (19.0) & 0.005 & 21/73 (28.8) & 23/68 (33.8) & 0.517 & 44/141 (31. 2) & \\
\hline Total & $124 / 254(48.8)$ & $34 / 143(23.8)$ & $<0.001$ & $87 / 202(43.1)$ & $71 / 195$ (36. 4) & 0.175 & 158/397 (39.8) & \\
\hline
\end{tabular}

ECC early childhood caries, CF caries-free

\section{Results}

Distribution of C.albicans in the dental plaque of Han and Uygur children

Based on the proportion of local population distribution, 256 Uygur and 141 Han children were enrolled in the study. C.albicans detection rate was significantly higher in Uygur children than in $\operatorname{Han}\left(44.5 \%\right.$ vs. $31.2 \% ; X^{2}=6.739$, $P=0.009)$, and in the ECC group than in the CF group of Uygur children (52. $3 \%$ vs. $27.5 \% ; X^{2}=13.665, P<0.001$ ) and in the ECC group than in the CF group of Han children $\left(41.0 \%\right.$ vs. $\left.19.0 \% ; X^{2}=7.842, P=0.005\right)$. Among the Uygur children, the detection rate of C.albicans was significantly higher in male than in female children(51. $2 \%$ vs. $\left.37.8 \% ; X^{2}=4.630, P=0.031\right)$ (Table 2 ).

\section{C. albicans identification}

After $24 \mathrm{~h}$ culture on CAC plates, the C.albicans clinical isolates formed white or light green, flat, and round colonies; after $48 \mathrm{~h}$, the colonies appeared emerald green, and had a smooth surface. Gram-positive C.albicans cells were round and scattered (Fig. 1, left). In the germ-tube test, the germinated spores of C.albicans clinical isolates were circular, with slender hyphae (Fig. 1, right). PCR analysis confirmed that all suspected clinical isolates were indeed C.albicans, and a clear 250-bp band was observed (Fig. 2).

\section{C.albicans genotyping}

The 25S rDNA PCR products were resolved on agarose gels: genotype A, 450-bp band; genotype B, 840-bp band; genotype C, 450- and 840-bp bands (Fig. 3). It revealed that genotype A was dominant in both Han and Uygur children with ECC, but the constituent ratio did not differ significantly. In Uygur CF children, genotype $C$ was dominant, and the distribution between ECC and CF groups significantly differed. $\mathrm{A}, \mathrm{B}$, and $\mathrm{C}: P=0.2,0.407$, and 0.022, respectively; the differences in A-, B-, and C-genotype constituent ratios were not statistically significant(Table 3).

The acidogenicity, aciduricity, and adhesiveness of $C$. albicans The acidogenicity of C.albicans isolated from ECC and CF groups of Uygur children increased with increasing glucose concentration in the medium. When the concentration of glucose reached $0.1 \mathrm{~mol} \cdot \mathrm{L}^{-, 1}$ both the acidogenicity and growth of C.albicans were more pronounced in ECC group than in CF; the differences were statistically significant (acidogenicity, $P=0.004$; growth, $P=0.012$ ). C.albicans isolates were still alive at $\mathrm{pH} 4.0$ and 4. 5; the acidogenicity and aciduricity of isolates from the ECC group were higher than the isolates from the CF group ( $\mathrm{pH} 4.0, P=0.012 ; \mathrm{pH} 4$. 5, $P=0.029$ ). Finally, the average glass-wall adhesion ratio was higher in the isolates from the ECC group $(53.92 \% \pm 6.79 \%)$ than in isolates from the CF group (31. $12 \% \pm 5.45 \%, P=0.02)$.

\section{C.albicans sap activity}

As determined by the YNB-BSA-agar method, all strains showed Sap activity. The activity was significantly higher in ECC group isolates $(0.160 \pm 0.012)$ than in CF group $(0.217 \pm 0.031 ; t=7.713, P<0.001)$. Similarly, based on the results of the MTT assay, C.albicans Sap activity was

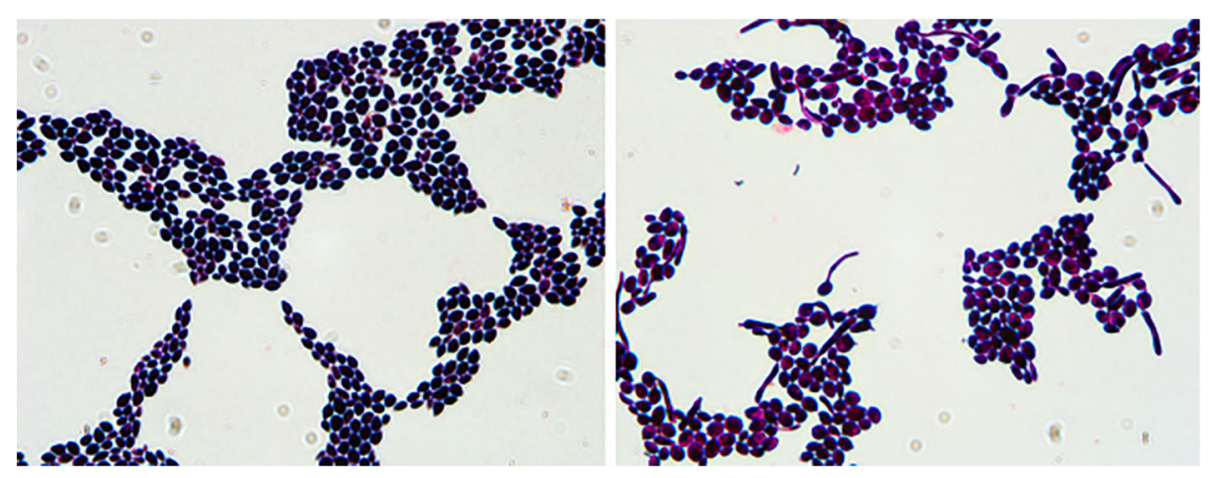

Fig. 1 Gram staining of C.albicans ( $\times 100$; left panel) and germ-tube test $(\times 100$;right panel) 


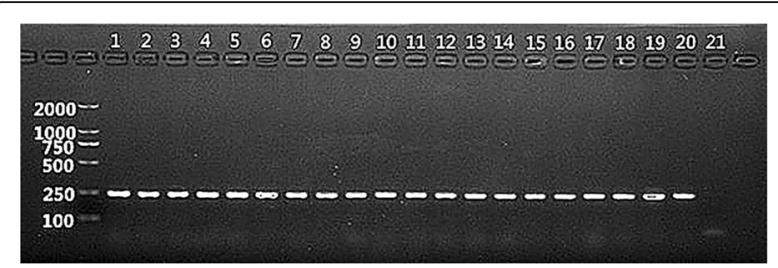

Fig. 2 PCR-based identification of C.albicans. A ca. 250-bp band was detected in all isolates after amplification(molecular marker is shown on the left). Lane 1: standard C.albicans strain ATCC 90028; lanes 2-10: C.albicans from Uygur children with early childhood caries (ECC); lanes 11-20: C. albicans from Uygur caries-free (CF) children; lane 21: negative control

significantly higher in ECC group isolates $(1.876 \pm 0.373)$ than in CF group $(1.166 \pm 0.348 ; t=6.226, P<0.001)$.

\section{SAP1-5 gene expression}

The SAP1-3 and SAP5 genes were expressed at higher levels in ECC group than in CF, but the difference in expression was only statistically significant for $S A P 2$ $(P<0.001)$ and SAP5 $(P=0.001)$ expression; conversely, $S A P 4$ expression was lower in ECC group than in CF, but the difference was not significant $(P=0.114)$.

\section{Cariogenicity of $C$. albicans of different genotypes: Factorial analysis}

By using $3 \times 2 \times 2$ factorial analysis, at $\mathrm{pH} 4.0$ and 4.5 the aciduricity did not differ between the different genotypes, but was higher in the ECC group than in the CF group isolates.

Acidogenicity C.albicans of different genotypes from ECC and CF groups in the presence of $0.1 \mathrm{~mol} \cdot \mathrm{L}^{-1}$ of glucose was compared using $3 \times 2$ factorial analysis; it significantly differed between the groups (group comparison, $P=0.020$; genotype comparison, $P=0.019$ ); ECC group: A > C > B; CF group: B $>$ A > C (Table 4).

C. albicans adhesion rate and Sap activity were examined using $3 \times 2$ factorial analysis, which revealed that these did not show genotype-dependent differences. Finally, factorial analysis of gene expression in ECC and CF group isolates revealed that only the expression of
SAP2 was significantly different in C.albicans of different genotypes in the ECC and CF groups (group comparison, $P=0.001$; genotype comparison, $P=0.020$ ); $S A P 2$ expression: ECC group, $\mathrm{A}>\mathrm{B}>\mathrm{C}$; $\mathrm{CF}$ group, $\mathrm{B}>\mathrm{A}>\mathrm{C}$ (Table 5,Fig. 4).

\section{Discussion}

The recent research into the aetiology of ECC has been focused on the relationship between C.albicans and ECC [16]. Klinke et al. verified that C.albicans is associated with an increased prevalence of caries [17]. In the current study, the C.albicans detection rate in the ECC group (48.8\%) was more than double of that in the CF group (23.8\%), which again demonstrated the close association of C.albicans with ECC.

The C.albicans detection rate was significantly higher in Uygur children than in Han $(P=0.009)$, in contrast to our previous study of Urumqi [18]. This discrepancy might be due to regional differences: compared with Urumqi, Kashgar is a more isolated city, with a higher proportion of Uygur people and unique customs. Hence, C.albicans distribution is likely affected not only by ethnic differences, but also by geographic differences.

We found that in the presence of $0.1 \mathrm{~mol} \cdot \mathrm{L}^{-1}$ of glucose, the acid produced by C.albicans caused the broth $\mathrm{pH}$ to drop from 7.00 to 4.06 , which is lower than the enamel demineralization $\mathrm{pH}$ threshold (5. 5) [19]; further, C.albicans acidogenicity and growth were both more pronounced in ECC group isolates than in CF group. This suggests that C.albicans isolates were strongly cariogenic in the presence of $0.1 \mathrm{~mol} \cdot \mathrm{L}^{-1}$ of glucose. Furthermore, the aciduricity and growth capacity of both ECC and CF group C.albicans isolates decreased as the initial $\mathrm{pH}$ was lowered; nevertheless, at $\mathrm{pH} 4.0$, C.albicans continued to produce acid, in agreement with the observations of Klinke et al. [18] This is in contrast with clinical isolates of S.mutans, whose growth is inhibited, and acidogenicity and aciduricity are abolished at $\mathrm{pH}$ below 5.0 [20], indicating that in an acidic environment, the acidogenicity and aciduricity of C.albicans are more pronounced than in S.mutans.

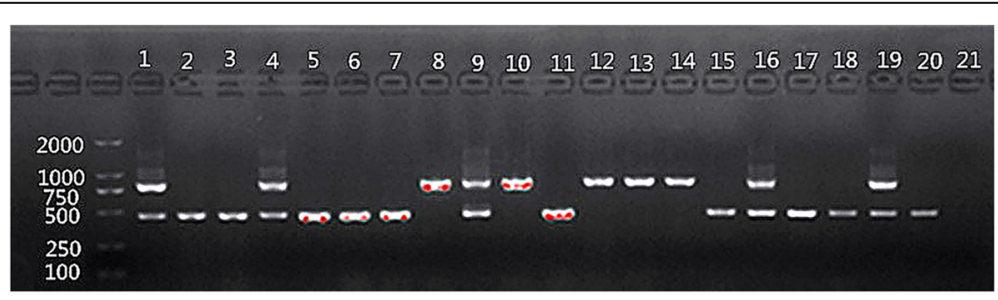

Fig. 3 C.albicans genotyping. Lanes 2, 3, 5-7,11, 15, 17, 18, and 20: genotype A; lanes 8, 10, 12, 13, and 14: genotype B; lanes 1, 4, 9, 16, 19, and: genotype C; lane 21: negative control 
Table 3 Gene polymorphism of C.albicans isolates from Uygur and Han children with ECC or CF

\begin{tabular}{lllll}
\hline Ethnicity & A-genotype (\%) & B-genotype (\%) & C-genotype (\%) & P \\
\hline Han ECC & $13(65)$ & $4(20)$ & $3(15)$ & 0.827 \\
Uygur ECC & $11(55)$ & $5(25)$ & $4(20)$ & \\
Uygur CF & $6(30)$ & $2(10)$ & $12(60)$ & \\
P(Uygur ECC/CF) & 0.2 & 0.407 & 0.022 & 0.035 \\
\hline
\end{tabular}

ECC early childhood caries, CF caries-free

C.albicans gene polymorphism in Uygur and Han children with ECC: $n=40$

theoretical frequency $1 \leqq \mathrm{~T} \leqq 5$; Fisher's exact test, $P=0.827$

C.albicans gene polymorphism in ECC and CF groups of Uygur children: $n=40$;

theoretical frequency $1 \leqq \mathrm{~T} \leqq 5$; Fisher's exact test, $P=0.035$

C.albicans is able to colonize the oral cavity because of its strong adhesion ability. The activity of C.albicans Saps has been shown to be associated with C.albicans invasiveness, and cell adhesion is proportional to the amount of produced Saps [21]. Recently, considerable progress has been made in the C.albicans Sap research. Taylor et al. reported that Sap5 is expressed early in infection; Sap4 is expressed in the final infection stage, while the expression of Sap5 is reduced [22]. The difference in Sap expression is linked to the infection environment [23], and this might due to the adaptation of Sap to the specific host environment, promoting an overlap in the activities of distinct Sap proteins produced in diverse environments and their roles. The results of the current study differ from those of $\mathrm{Li}$ et al. [24], who reported significantly higher or lower expression of SAP1 and SAP4 respectively in ECC group isolates than in $\mathrm{CF}$ group. This discrepancy might be associated with the differences between the selected populations, geographical differences, or ethnic differences, but further investigation is required to clarify this issue. In the future, DNA-chip technology and microarray analysis may allow the elucidation of the relationship between the expression of individual SAP genes and the biological activity or virulence of C.albicans, facilitating the development of new infection prevention strategies based on targeting of specific $S A P$ genes.

Genotyping is an effective and classical molecular biology approach for studying the relationship between species, clarifying the association between different

Table 4 Acidogenicity of A-, B-, and C-genotype C.albicans isolates from the ECC and CF groups in the presence of 0.1 mol.L-1 glucose

\begin{tabular}{llll}
\hline Genotype & ECC & CF & $P$ \\
\hline A & $3.092 \pm 0.230$ & $2.772 \pm 0.125$ & 0.019 \\
B & $2.656 \pm 0.308$ & $2.825 \pm 0.078$ & \\
C & $2.870 \pm 0.424$ & $2.617 \pm 0.193$ & \\
P & 0.020 & & \\
\hline
\end{tabular}

$E C C$ early childhood caries, CF caries-free ECC group: $\mathrm{A}>\mathrm{C}>\mathrm{B} ; \mathrm{CF}$ group: $\mathrm{B}>\mathrm{A}>\mathrm{C}$
Table 5 SAP2 expression in A-, B-, and C-genotype C. albicans: differences between the ECC and CF group isolates

\begin{tabular}{llll}
\hline Genotype & ECC & CF & $P$ \\
\hline A & $3.644 \pm 1.415$ & $0.910 \pm 0.897$ & 0.020 \\
$B$ & $2.617 \pm 1.481$ & $1.995 \pm 0.332$ & \\
$C$ & $1.783 \pm 1.373$ & $0.435 \pm 0.652$ & \\
$P$ & 0.001 & & \\
\hline ECC early childhood caries, CF caries-free & &
\end{tabular}

SAP2 expression: ECC group, $\mathrm{A}>\mathrm{B}>\mathrm{C}$; $\mathrm{CF}$ group, $\mathrm{B}>\mathrm{A}>\mathrm{C}$

strains. The genotype of C.albicans continually changes after host infection to enable fungal adaptation to new environments [25]. In this regard, the transmission and colonization of oral microorganisms is not only limited by the source and route of infection, but is also affected by the host's genetic background, lifestyle, and oral microbial environment [26]. The constitution of genotype $\mathrm{A}$ in the current study is the same as reported by $\mathrm{Wu}$ et al. [10], and da Silva-Rocha et al. [27], implying that the C.albicans of genotype A might cause more caries. Genotype C of C.albicans was dominant in Uygur CF children, and the difference between Uygur ECC and CF group isolates was statistically significant. This results differ from those of Qiu et al [28], possibly on account of location differences, and the unique eating habits and lifestyles of the subjects. C.albicans exhibits extremely high gene polymorphism in hosts from different ethnic groups and in hosts with different degree of caries [[10], [18]] this suggests that more attention should be devoted to genotype variation and host microecological balance when addressing such topics as C.albicans pathogenicity, prevention of dysbacteriosis, and drug selection. In the current study, the constituent C.albicans genotype was different, probably because of differences in pathogenicity, or selective growth of C.albicans in different host environments. The following conclusion may hence be drawn pertaining to the differences in genotype constitution: the mouth microenvironment differs among different groups of people, and thus the colonization capacity of different genotypes of C.albicans is also different.

In conclusion, dental caries develops when the dynamic equilibrium of the oral microflora is destroyed. The results might be correlate with the differences in population genetics and ethnicity, geographical distribution, and eating habits. Further investigation is required to verify that. To fully understand the ecological processes of caries formation, future molecular biology research is essential: sophisticated methods, such as metabolomics and metagenomics, are needed for the reconstruction of microbial metabolism networks and the dynamic stability of physiological mechanisms within a dental biofilm. 


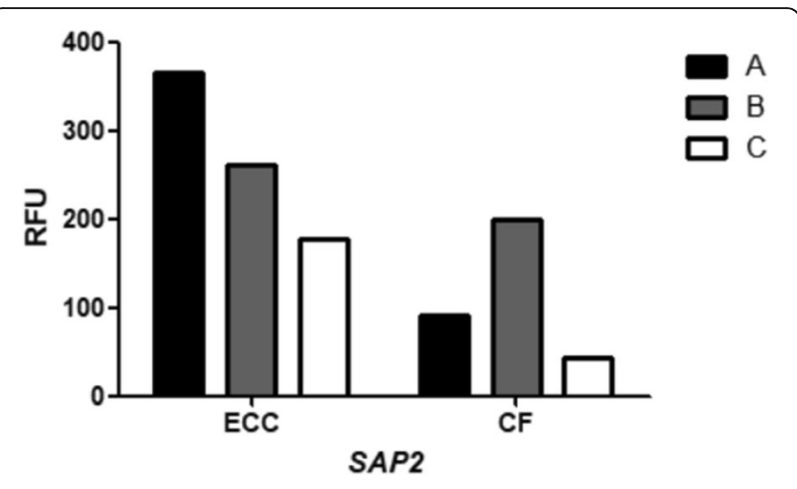

Fig. 4 SAP2 expression in A-, B-, and C-genotype C.albicans: differences between the ECC and CF group isolates

\section{Conclusions}

The strong acidogenicity and aciduricity, Sap activity, and high SAP2 and SAP5 expression might be closely associated with ECC. C.albicans potentially plays a key role in the progression of caries, which most readily affects genotype A carriers and could be attributed to person-to-person environmental variation.

\section{Abbreviations}

BSA: Bovine Serum Albumin; CAC: Chromagar Candida; ECC: Early childhood caries; MTT: Methy thiazolyl tetrazolium; PCR: Polymerase Chain Reaction; Sap: Secreted aspartyl proteinase; SDA: Sabourand Dextrose Agar; YNB: Yeast Nitrogen Base

\section{Acknowledgements}

Not applicable.

\section{Funding}

This study was funded by grant funding from the National Natural Science Foundation of China (grant no. 81760194) and the College of Xinjiang Medical University of China. The funders had no role in study design, data collection and analysis, decision to publish, or preparation of the manuscript. The authors declare no potential conflicts of interest with respect to the authorship and/or publication of this article.

\section{Availability of data and materials}

The data were upload as additional supporting files.

\section{Authors' contributions}

WTZ contributed to Data curation,Formal analysis, Investigation,Methodology, Software, Validation, Visualization and Writing original draft. YL contributed to Data curation,Formal analysis,Investigation and Methodology. JL contributed to Investigation,Software and Validation. AA contributed to Conceptualization,Data curation,Formal analysis and Software. JZ contributed to

Conceptualization,Funding acquisition,Project administration, Resources, Supervision,Validation,Visualization and Writing-review \& editing. All authors gave final approval and agree to be accountable for all aspects of the work.

\section{Ethics approval and consent to participate}

This study was approved by the First Affiliated Hospital of Xinjiang Medical Ethics Committee (ethical review number 20150214-162), and the local heath administrative departments.The parents of all study participants provided written informed consent.

\section{Consent for publication}

Not applicable.

\section{Competing interests}

The authors declare that they have no competing interests.

\section{Publisher's Note}

Springer Nature remains neutral with regard to jurisdictional claims in published maps and institutional affiliations.

\section{Author details}

${ }^{1}$ Department of Endodontics, The First Affiliated Hospital of Xinjiang Medical University, Urumqi, Xinjiang 830054, China. ${ }^{2}$ Xinjiang Kashgar First people's

Hospital, Xinjiang 844000, China.

Received: 24 July 2018 Accepted: 8 November 2018

Published online: 05 December 2018

\section{References}

1. Benjamin RM. Oral health: the silent epidemic[J]. Public Health Rep. 2010; 125(2):158-9.

2. Nobile CG, Fortunato L, Bianco A, Pileggi C, Pavia M. Pattern and severity of early childhood caries in southern Italy:a preschool-based cross-sectional study[J]. BMC Public Health. 2014;14(1):1-12

3. Doğan D, Dülgergil CT, Mutluay AT, Yıldırım I, Hamidi MM, Çolak H. Prevalence of caries among preschool-aged children in a central Anatolian population[J]. J Nat Sci Biol Med. 2013;4(2):325-9.

4. Melo Nunes AM, da Silva AA, Coelho Alves CM, Hugo FN, Costa Ribeiro CC. Factors underlying the polarization of early childhood caries within a highrisk population[J]. BMC Public Health. 2014;14(22):988-92.

5. Marchant S, Brailsford SR, Twomey AC, Roberts GJ, Beighton D. The predominant microflora of nursing caries lesions. Caries Res. 2001;35(6):397-406.

6. Yang XQ, Zhang Q, Lu LY, Yang R, Liu Y, Zou J. Genotypic distribution of Candida albicans in dental biofilm of Chinese children associated with severe early childhood caries. Arch Oral Biol. 2012;57(8):1048-53.

7. Fan MW, Zhou XD. Endodontics.4th. ed.Beijing: PEOPLE'S MEDICAL PUBLISHING HOUSE.2012.

8. Hintao J, Teanpaisan R, Chongsuvivatwong V, Ratarasan C, Dahlen G. The microbiological profiles of saliva, supragingival and subgingival plaque and dental caries in adults with and without type 2 diabetes mellitus. Oral Microbiol Immunol. 2007;22(3):175-81.

9. Gao S, Zhao W, Qiu RM, Lin Y. Relationship between secreted aspartyl proteinase of Candida albicans and severe early childhood caries. Chin J Stomatol Res. 2010;3(5):20-3.

10. Wu N, Lin J, Wu L, Zhao J. Distribution of Candida albicans in the oral cavity of children aged 3-5 years of Uygur and Han nationality and their genotype in caries-active groups. Genet Mol Res. 2015;14(1):748-57.

11. A yinuer A, Zhao J, Ma L, Lian BJ. An epidemiological study of Uyghurs and Han infant caries in KashgarChina. Health Statistics. 2014;31(3):234-7.

12. Wu XS. Clinical study sample size estimation. 2nd.ed ed. Beijing: PEOPLE'S MEDICAL PUBLISHING HOUSE; 2008. p. 145-208.

13. Lian BJ, Zhao J, Liu ZH, Nurbiye M. Comparative study of Uighur children of different caries sensitive clinical isolates of Streptococcus Mutans biofilm State's extracellular polysaccharide synthesis capacity. J Oral Sci Res. 2012; 28(4):325-30.

14. Barros LM, Boriollo MF, Alves AC, Klein MI, Gonçalves RB, Höfling JF. Genetic diversity and exoenzyme activities of Candida albicans and Candida dubliniensis isolated from the oral cavity of Brazilian periodontal patients. Arch Oral Biol. 2008;53(12):1172-8.

15. Mendes A, Mores AU, Carvalho AP, Rosa RT, Samaranayake LP, Rosa EA. Candida albicans biofilms produce more secreted aspartyl protease than the planktonic cells. Biol Pharm Bull. 2007;30(9):1813-5.

16. Maria B, Irastorza RM, Diego C, Marcelo O, Osvaldo C. Mechanisms of interaction between Candida albicans and Streptococcus mutans: an experimental and mathematical modelling study. Acta Odontol Scand. 2013; 719(3-4):416-23.

17. Klinke T, Guggenheim B, Klimm W, Thurnheer T. Dental Caries in Rats Associated with Candida albicans. Caries Res. 2011;45(2):100-6.

18. Wu N, Liu F, Zhao J. Distribution of Oral Candida Albicans and its correlation with early child caries in Uygur and Chinese children. J Oral Sci Res. 2013; 29(4):338-41.

19. Fan MW. New Development of Stomatology. 2nd.ed ed. Beijing: PEOPLE'S MEDICAL PUBLISHING HOUSE; 2015.

20. Liu ZH. Study on the ability of acidogenecity, aciduricity and genetic diversity within aciduric virulence of Streptococus mutuns from caries-active and caries-free individuals in Urumqi Uygur children[dissertation].[Xinjiang China]2015.Xinjiang Medical University. 
21. Sun HY, Zou X, Zou JC. Current research status on the virulence of common pathogenic Candida. Chinese Journal of Microecology. 2013;25(5):604-8.

22. Taylor BN, Staib P, Binder A, Biesemeier A, Sehnal M, Rllinghoff M, Morschhuser J, Schrppel K. Profile of Candida albicans-secreted aspartic proteinase elicited during vaginal infection. Infect Immun. 2005;73(3):1828-35.

23. Ge YP, Hu Y. Secreted aspartic proteinase genes differential expression and influencing factors. Int J Oral Science. 2010;37(6):732-5.

24. Li WQ, Yu DS, Gao S, Lin JC, Chen ZY, Zhao W. Role of Candida albicans secreted aspartyl proteinases(saps)in severe early childhood caries. Int J Mol Sci. 2014;15(16):10766-79.

25. Paula S, Leonor G, Alexandra C, Cintia A, Acacio GR, Cidalia PV, Antonio A, Celia P. New microsatellite multiplex PCR for Candida albicans strain typing reveals microevolutionary changes. J Clin Microbiol. 2005;43(8):3869-76.

26. Chen KW, Chen YC, Lo HJ, Frank CO, Wang TH, Lin CY, Li SY. Multilocus sequence typing for analyses of Clonality of Candida albicans strains in Taiwan. J Clin Mierobiol. 2006;44(6):2172-8.

27. Silva-Rocha WP, Lemos VL, Svidizisnki TI, Milan EP, Chaves GM. Candida species distribution, genotyping and virulence factors of Candida albicans isolated from the oral cavity of kidney transplant recipients of two geographic regions of Brazil. BMC Oral Health. 2014;14(1):1420-5.

28. Qiu RM, Li WQ, Lin Y, Yu DS, Zhao W. Genotypic diversity and cariogenicity of Candida albicans from children with early childhood caries and cariesfree children. BMC Oral Health. 2015;15(1):144.

Ready to submit your research? Choose BMC and benefit from:

- fast, convenient online submission

- thorough peer review by experienced researchers in your field

- rapid publication on acceptance

- support for research data, including large and complex data types

- gold Open Access which fosters wider collaboration and increased citations

- maximum visibility for your research: over $100 \mathrm{M}$ website views per year

At $\mathrm{BMC}$, research is always in progress.

Learn more biomedcentral.com/submissions 